\title{
Normative values for stool frequency and form using Rome III diagnostic criteria for functional constipation in adults: systematic review with meta-analysis
}

\author{
Larry E. Millera, Alvin Ibarrab ${ }^{b}$, Arthur C. Ouwehand ${ }^{b}$, Angela K. Zimmermann ${ }^{a}$ \\ Miller Scientific Consulting, Inc, Asheville, NC, USA; DuPont Nutrition and Health, Kantvik, Finland
}

\begin{abstract}
When designing clinical trials focused on functional constipation therapies, understanding the normative values of populations selected using the Rome III criteria is important for estimating baseline symptom severity, and for power analysis and sample size calculations. The objective of this review was to determine normative ranges for stool frequency and form in adults with functional constipation (Rome III criteria). Eligible studies reported stool frequency or form; random effects meta-analysis was performed with subgroup analyses to explore sources of heterogeneity. A total of 25 studies (43 groups, 2292 subjects) were included. Pooled estimates were 2.7 (95\% CI 2.4-3.0) for weekly stools and 2.4 (95\% CI 2.1-2.6) for stool form (Bristol scale). Heterogeneity was high for both outcomes (both $\mathrm{I}^{2}=96 \%, \mathrm{P}<0.001$ ). Subgroup analysis revealed that weekly bowel movement frequency was higher in larger than in smaller studies (3.1 vs. 2.3, $\mathrm{P}<0.001)$ and in studies conducted in Europe compared with those in the Americas (3.1 vs. 2.2, $\mathrm{P}=0.02$ ). For stool form, the use of a daily diary versus subject recall was the sole explanatory variable $(2.5$ vs. $2.1, \mathrm{P}<0.05)$. We conclude that adults with functional constipation have significant variation in stool frequency and form, explained in part by geography and study design.
\end{abstract}

Keywords Constipation, functional, meta-analysis, stool, systematic review, Rome III

Ann Gastroenterol 2016; 30 (1): 1-7

\section{Introduction}

Chronic constipation is a common disorder of colonic or anorectal function that affects $14 \%$ of adults worldwide [1]. While constipation may develop secondarily to disease, medication, or surgery, most cases are idiopathic in nature. Accurate diagnosis is often hindered by the heterogeneous presentation of symptoms and by the substantial symptom overlap with other gastrointestinal disorders, such as constipation-predominant irritable bowel syndrome [2,3]. The Rome Diagnostic Criteria have attempted to refine the diagnosis of functional gastrointestinal disorders by proposing more objective and

${ }^{a}$ Miller Scientific Consulting, Inc., Asheville, NC, USA (Larry E. Miller, Angela K. Zimmermann); 'buPont Nutrition and Health, Kantvik, Finland (Alvin Ibarra, Arthur C. Ouwehand)

Conflict of Interest: This work was supported by Danisco Sweeteners (Kantvik, Finland)

Correspondence to: Larry E. Miller, PhD, Miller Scientific Consulting, Inc., 1854 Hendersonville Road, \#231, Asheville, NC 28803, USA, e-mail: larry@millerscientific.com

Received 13 September 2016; accepted 25 October 2016; published online 01 December 2016

DOI: https://doi.org/10.20524/aog.2016.0108 standardized diagnostic guidelines. According to Rome III [4], a diagnosis of functional constipation is made when at least two of the following criteria are met for the last 3 months with symptom onset at least 6 months prior to diagnosis: a) straining on $>25 \%$ of defecations; b) lumpy or hard stools on $>25 \%$ of defecations; c) sensation of incomplete evacuation on $>25 \%$ of defecations; d) sensation of anorectal obstruction/ blockage on $>25 \%$ of defecations; e) manual maneuvers on $>25 \%$ of defecations; and f) less than 3 defecations per week. In addition, loose stools must be rarely present without the use of laxatives and irritable bowel syndrome must not be present. However, even when these criteria are applied, the spectrum of constipation symptoms may remain broad. This may cause problems in the design of clinical trials focused on functional constipation therapies, since estimating baseline symptom severity with reasonable accuracy is necessary for power analysis and sample size calculations. In accordance with the International Council for Harmonisation (ICH) E6 guidance [5], normative test values should be established prior to execution of a clinical trial. To the authors' knowledge, such data do not currently exist for common endpoints in functional constipation clinical trials, such as stool frequency and consistency. The objective of this systematic review and metaanalysis was to determine normative ranges for stool frequency and form in adults diagnosed with functional constipation according to the Rome III criteria. A secondary goal of this 
research was to identify potential sources of heterogeneity in these outcomes.

\section{Materials and methods}

\section{Literature search}

Medline (including in-process citations), EMBASE, and Scopus databases were searched for studies, regardless of study design, that reported stool frequency or stool form in adults with functional constipation according to the Rome III criteria. Search terms included "bowel function"; "chronic constipation"; "constipat*"; "functional constipation"; "functional gastrointestinal disorder"; "idiopathic constipation"; and "Rome III". Additionally, manual searches were conducted using the Directory of Open Access Journals, Google Scholar, and the reference lists of included papers and other relevant meta-analyses. Searches were restricted to papers published between 2006 and 2016, the former date coinciding with the development of the Rome III guidelines. The final search was conducted in July 2016.

\section{Study selection}

Two researchers independently selected studies for inclusion in the review. Disagreements were resolved by consensus. Titles and abstracts were screened to exclude all non-English papers, review articles, commentaries, letters, case reports, and obviously irrelevant manuscripts. Full-text versions of the remaining manuscripts were retrieved and reviewed. Studies of patients with functional constipation using the Rome III criteria that reported baseline stool frequency or stool form were included. Studies were excluded if subjects were less than 18 years of age; functional constipation was secondary to disease, surgery, or medication use; the Rome III diagnostic criteria were not applied; or the Rome III diagnostic criteria were modified to mandate additional study inclusion criteria involving thresholds for stool frequency or form. Data were extracted from eligible peer-reviewed articles by one author and then verified by a second author. Data extraction discrepancies were resolved by consensus.

\section{Outcomes}

Main outcomes were stool frequency and stool form. Stool frequency was defined as the number of self-reported bowel movements per week; data on spontaneous bowel movements and complete bowel movements were not considered. Stool form was extracted from studies that utilized the Bristol Stool Form Scale (BSFS) [6], where values of 1 or 2 indicate constipation, 3 and 4 are considered ideal, and 5 to 7 are indicative of diarrhea or urgency.

\section{Data analysis}

A random effects meta-analysis model was developed based on the a priori assumption that treatment effects would be heterogeneous among studies. The pooled estimate and 95\% confidence intervals (95\% CI) were calculated for each main outcome. A forest plot was used to illustrate the individual study findings and the random effects meta-analysis results. Heterogeneity of outcomes among studies was quantified with the $\mathrm{I}^{2}$ statistic, where values of $\leq 25 \%, 50 \%$, and $\geq 75 \%$ represent low, moderate, and high heterogeneity, respectively [7]. Subgroup analyses and meta-regression were undertaken to explore potential sources of heterogeneity in outcomes. For these analyses, values of $\mathrm{P}<0.05$ were considered statistically significant. Statistical analyses were performed using Comprehensive Metaanalysis version 2.2 (Biostat, Englewood, NJ, USA).

\section{Results}

\section{Study selection}

From a total of 407 records that were screened for eligibility, 25 studies (43 groups) representing 2292 unique subjects were included in the meta-analysis. A flow diagram illustrating the study identification and selection is shown in Fig. 1.

\section{Study and patient characteristics}

Median values were age 41 years (range: 21 to 82 years), $77 \%$ female (range: $0 \%$ to $100 \%$ ), $25 \mathrm{~kg} / \mathrm{m}^{2}$ body mass index (range: $19-27 \mathrm{~kg} / \mathrm{m}^{2}$ ), and 7 years symptom duration (range: $1-21$ years). Functional constipation was diagnosed by a physician in $15(60 \%)$ studies or via questionnaire only in 10 (40\%) studies. Bowel symptoms were determined by daily diaries in 14 (56\%) studies or by subject recall in 11 (44\%) studies (Table 1).

\section{Stool frequency}

In 20 studies (35 groups), weekly stool frequency was 2.7 (95\% CI 2.4-3.0), with a range of 1.1-4.6 (Fig. 2). Heterogeneity in stool frequency was high among studies $\left(\mathrm{I}^{2}=96 \%, \quad \mathrm{P}<0.001\right)$. In subgroup analysis, statistically significant sources of heterogeneity included sample size and geographic location. Weekly bowel movement frequency was higher in larger than in smaller studies (3.1 vs. $2.3, \mathrm{P}<0.001)$. Stool frequency also varied with geography, with 3.1 bowel movements per week in European studies compared with 2.2 in the Americas. No other study or subject factors influenced weekly stool frequency (Table 2).

\section{Stool form}

In 16 studies (26 groups), stool form on the BSFS was 2.4 (95\% CI 2.1-2.6), with a range of 1.3-4.0 (Fig. 3). 


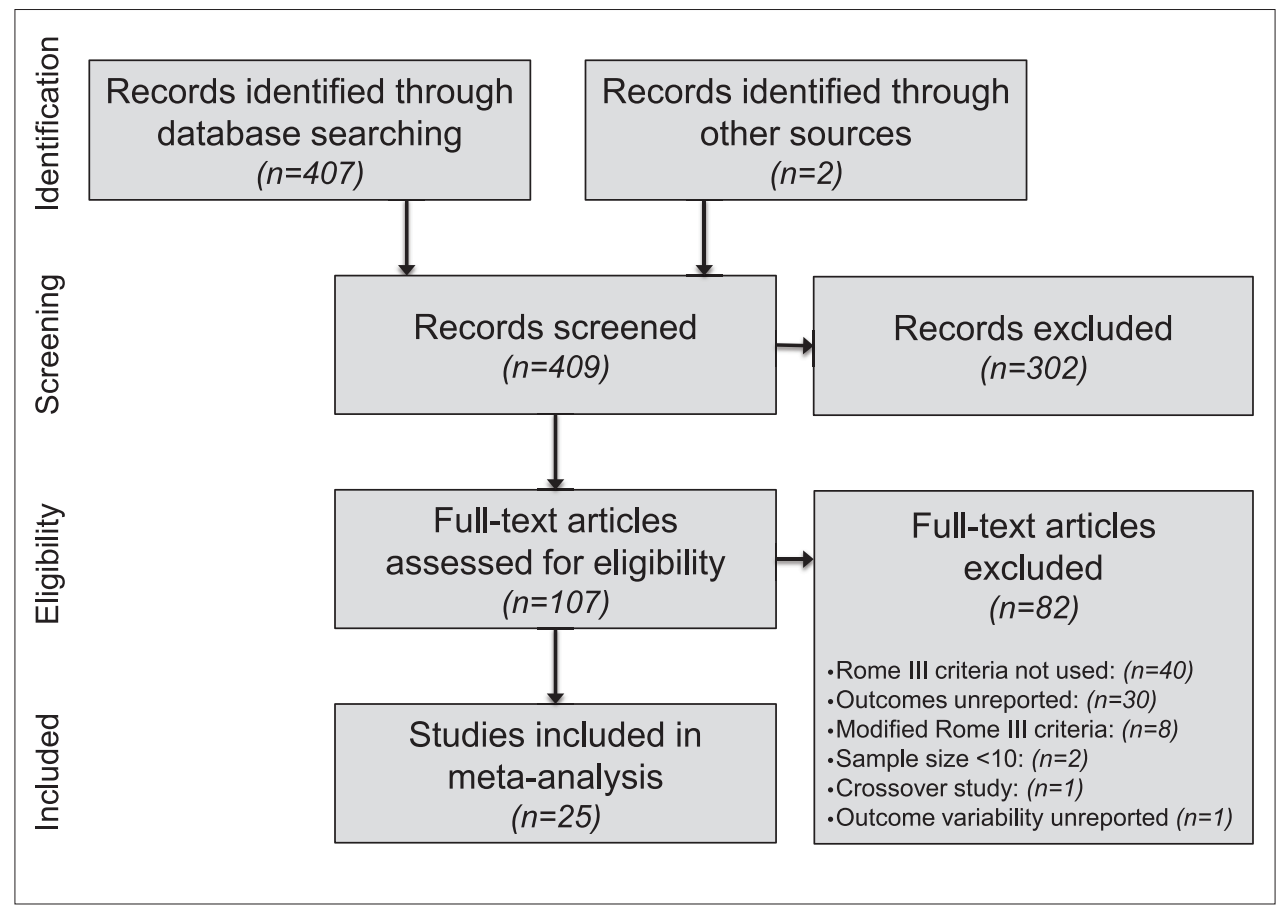

Figure 1 Study flow diagram

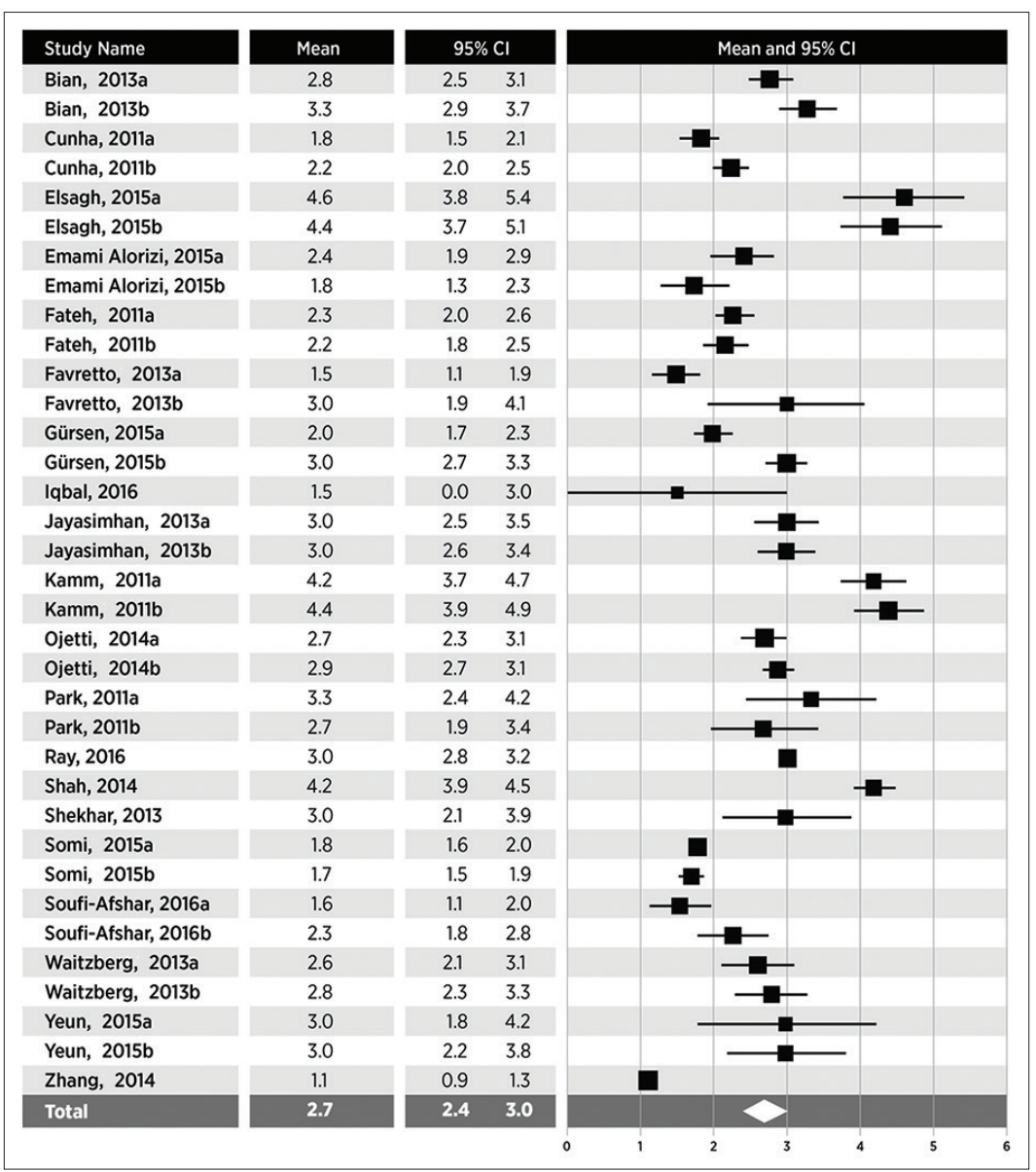

Figure 2 Weekly stool frequency in adults with functional constipation. Stool frequency estimates from random effects meta-analysis. A pooled estimate (diamond) and $95 \%$ confidence interval (diamond width) summarizes the effect size 
Table 1 Study and subject characteristics

\begin{tabular}{lccccccc}
\hline Study Country & $\mathrm{N}$ & $\begin{array}{c}\text { Age } \\
\text { (years) }\end{array}$ & $\begin{array}{c}\text { Female } \\
(\%)\end{array}$ & $\begin{array}{c}\text { BMI } \\
\left(\mathrm{kg} / \mathrm{m}^{2}\right)\end{array}$ & $\begin{array}{c}\text { Symptom } \\
\text { duration } \\
\text { (years) }\end{array}$ & $\begin{array}{c}\text { Physician } \\
\text { diagnosis }\end{array}$ & $\begin{array}{c}\text { Bowel } \\
\text { Diary* }\end{array}$ \\
\hline
\end{tabular}

\begin{tabular}{|c|c|c|c|c|c|c|c|c|}
\hline Bian, 2013 [11] & China & 120 & - & - & - & - & No & 2 \\
\hline Cunha, 2011 [12] & Brazil & 76 & 35 & 100 & 25 & - & Yes & 1 \\
\hline Elsagh, 2015 [13] & Iran & 110 & 42 & 71 & - & 7 & Yes & 0 \\
\hline Emami Alorizi, 2015 [14] & Iran & 100 & 44 & 75 & 26 & - & Yes & 0 \\
\hline Erdogan, 2016 [15] & United States & 72 & 43 & 92 & - & - & No & 1 \\
\hline Fateh, $2011[16]$ & Iran & 60 & 23 & 0 & - & 1 & No & 0 \\
\hline Favretto, 2013 [17] & Brazil & 30 & 39 & 100 & 27 & - & No & 0 \\
\hline Gürsen, 2015 [18] & Turkey & 50 & 39 & 92 & 24 & 8 & Yes & 0 \\
\hline Iqbal, 2016 [19] & United Kingdom & 20 & 39 & 80 & - & 6 & Yes & 1 \\
\hline Jayasimhan, 2013 [20] & Malaysia & 108 & 39 & 62 & - & 1 & No & 0 \\
\hline Kamm, 2011 [21] & United Kingdom & 369 & 55 & 75 & 26 & 21 & No & 2 \\
\hline Kim, 2015 [22] & South Korea & 30 & 35 & 70 & 21 & - & Yes & 1 \\
\hline Ojetti, 2014 [23] & Italy & 40 & 36 & 60 & - & - & Yes & 0 \\
\hline Park, 2011 [24] & South Korea & 25 & 37 & 100 & 22 & - & Yes & 1 \\
\hline Polymeros, 2014 [25] & Greece & 39 & 56 & 87 & 24 & - & Yes & 2 \\
\hline Ray, 2016 [26] & India & 224 & 63 & 46 & - & - & Yes & 0 \\
\hline Riezzo, 2012 [27] & Italy & 20 & 39 & 85 & 24 & 5 & Yes & 1 \\
\hline Shah, 2014 [28] & India & 74 & 53 & - & - & 2 & Yes & 0 \\
\hline Shekhar, 2013 [2] & United Kingdom & 11 & 38 & 100 & 23 & - & Yes & 1 \\
\hline Somi, 2015 [29] & Iran & 40 & 21 & 40 & - & - & Yes & 1 \\
\hline Soufi-Afshar, 2016 [30] & Iran & 68 & 50 & 59 & 26 & 11 & No & 2 \\
\hline Waitzberg, 2013 [31] & Brazil & 99 & - & 100 & 26 & - & No & 0 \\
\hline $\mathrm{Wu}, 2014$ [32] & China & 455 & 46 & 82 & - & 9 & Yes & 1 \\
\hline Yeun, 2015 [33] & South Korea & 40 & 82 & 75 & 19 & - & No & 0 \\
\hline Zhang, 2014 [34] & China & 12 & 60 & 67 & - & - & No & 1 \\
\hline
\end{tabular}

${ }^{\star} 0$, no diary; 1, 1-week; and 2, 2-week bowel diary used to assess bowel symptoms

BMI, body mass index

Heterogeneity in stool frequency was high among studies $\left(I^{2}=96 \%, P<0.001\right)$. By subgroup analysis, the only variable that contributed significantly to this heterogeneity was the method of bowel symptom assessment. BSFS scores were higher in studies that assessed bowel symptoms using a daily diary than in those that depended on subject recall $(2.5$ vs. $2.1, \mathrm{P}<0.05)$. The use of a 1-week or a 2-week daily diary had no effect on the reported stool form. No other study or subject factors influenced stool form (Table 3).

\section{Relationship between stool frequency and form}

In 12 studies (18 groups), stool frequency and form were reported. In meta-regression, a weak but statistically significant positive relationship was noted between bowel movements per week and stool form scores $\left(\mathrm{R}^{2}=13 \%, \mathrm{P}<0.001\right)$ (Fig. 4).

\section{Discussion}

This systematic review and meta-analysis attempted to establish normative ranges for stool frequency and form in adults with functional constipation according to the Rome III criteria. Despite the use of a common diagnostic tool in all studies, high heterogeneity in stool frequency and form was observed. Based on subgroup analysis results, differences in main outcomes among studies were mainly influenced by geography and study design factors, but not subject characteristics.

As expected, BSFS scores were lower than in healthy adults. Pooled stool form score on the BSFS was 2.4 in this metaanalysis, compared to 3.6 reported in a healthy population [8]. Similarly, pooled weekly stool frequency was 2.7 , compared to 7.7 bowel movements per week in healthy adults [8]. It is not surprising that the correlation between stool frequency and form was weak, and that different factors influenced 
Table 2 Subgroup analysis of effects of study- and subject-related factors on stool frequency

\begin{tabular}{|c|c|c|c|c|}
\hline Variable & Groups & Estimate & $95 \% \mathrm{CI}$ & $\mathrm{P}$-value \\
\hline \multicolumn{5}{|l|}{$\begin{array}{l}\text { Sample size per } \\
\text { group* }\end{array}$} \\
\hline $\mathrm{n} \geq 35$ & 14 & 3.1 & $2.6-3.5$ & $<0.01$ \\
\hline $\mathrm{n}<35$ & 19 & 2.3 & $2.0-2.6$ & \\
\hline \multicolumn{5}{|l|}{$\begin{array}{l}\text { Geographic } \\
\text { location }\end{array}$} \\
\hline Europe & 8 & 3.1 & $2.5-3.6$ & $<0.05$ \\
\hline Asia & 21 & 2.7 & $2.3-3.1$ & \\
\hline Americas & 6 & 2.2 & $1.8-2.6$ & \\
\hline \multicolumn{5}{|l|}{ Age $^{*}$} \\
\hline$\geq 41$ years & 14 & 3.1 & $2.4-3.7$ & 0.11 \\
\hline$<41$ years & 15 & 2.5 & $2.2-2.7$ & \\
\hline \multicolumn{5}{|l|}{$\begin{array}{l}\text { Bowel symptom } \\
\text { assessment }\end{array}$} \\
\hline Bowel diary & 14 & 2.5 & $2.0-2.9$ & 0.20 \\
\hline Subject recall & 21 & 2.8 & $2.5-3.1$ & \\
\hline \multicolumn{5}{|l|}{ Female sex ${ }^{*}$} \\
\hline$\geq 77 \%$ & 12 & 2.6 & $2.2-3.1$ & 0.66 \\
\hline$<77 \%$ & 16 & 2.8 & $2.3-3.2$ & \\
\hline \multicolumn{5}{|l|}{$\begin{array}{l}\text { Symptom } \\
\text { duration }\end{array}$} \\
\hline$\geq 7$ years & 6 & 3.1 & $2.1-4.2$ & 0.83 \\
\hline$<7$ years & 8 & 3.0 & $2.4-3.6$ & \\
\hline \multicolumn{5}{|l|}{$\begin{array}{l}\text { Body mass } \\
\text { index }\end{array}$} \\
\hline$\geq 25 \mathrm{~kg} / \mathrm{m}^{2}$ & 9 & 2.6 & $1.9-3.2$ & 0.86 \\
\hline$<25 \mathrm{~kg} / \mathrm{m}^{2}$ & 8 & 2.6 & $2.2-3.1$ & \\
\hline \multicolumn{5}{|l|}{$\begin{array}{l}\text { Physician } \\
\text { diagnosis }\end{array}$} \\
\hline Yes & 18 & 2.7 & $2.2-3.2$ & 0.92 \\
\hline No & 17 & 2.7 & $2.3-3.1$ & \\
\hline
\end{tabular}

${ }^{*}$ Subgroups divided at median value

†Variables sorted from lowest to highest subgroup P value

these outcomes. Stool frequency has been shown to be weakly related to stool form, a known surrogate for intestinal transit time [8].

The findings of this review are clinically meaningful for several reasons. First, although the clinical definition of constipation generally requires less than 3 bowel movements per week, $43 \%$ of the groups in this review had a stool frequency of 3 or more bowel movements per week. This finding is in agreement with a population-based study where the primary patient complaint was not stool frequency, but rather hard stools and straining [9]. Thus, stool frequency alone may be a poor indicator of constipation severity. Second, stool frequency and form are common primary endpoints in
Table 3 Subgroup analysis of effects of study- and subject-related factors on stool form

\begin{tabular}{|c|c|c|c|c|}
\hline Variable & Groups & Estimate & $95 \% \mathrm{CI}$ & P-value ${ }^{\dagger}$ \\
\hline \multicolumn{5}{|l|}{$\begin{array}{l}\text { Bowel symptom } \\
\text { assessment }\end{array}$} \\
\hline Bowel diary & 17 & 2.5 & $2.2-2.8$ & $<0.05$ \\
\hline Subject recall & 9 & 2.1 & $1.9-2.4$ & \\
\hline \multicolumn{5}{|l|}{ Female sex ${ }^{*}$} \\
\hline$\geq 77 \%$ & 14 & 2.5 & $2.2-2.8$ & 0.08 \\
\hline$<77 \%$ & 9 & 2.1 & $1.7-2.5$ & \\
\hline \multicolumn{5}{|l|}{$\begin{array}{l}\text { Sample size per } \\
\text { group* }\end{array}$} \\
\hline $\mathrm{n} \geq 35$ & 9 & 2.5 & $2.2-2.8$ & 0.18 \\
\hline $\mathrm{n}<35$ & 12 & 2.2 & $1.9-2.5$ & \\
\hline \multicolumn{5}{|l|}{$\begin{array}{l}\text { Physician } \\
\text { diagnosis }\end{array}$} \\
\hline Yes & 15 & 2.5 & $2.2-2.8$ & 0.22 \\
\hline No & 11 & 2.2 & $1.9-2.5$ & \\
\hline \multicolumn{5}{|l|}{$\begin{array}{l}\text { Geographic } \\
\text { location }\end{array}$} \\
\hline Europe & 7 & 2.2 & $1.9-2.5$ & 0.24 \\
\hline Asia & 13 & 2.4 & $2.0-2.8$ & \\
\hline Americas & 6 & 2.5 & $2.3-2.6$ & \\
\hline \multicolumn{5}{|l|}{$\begin{array}{l}\text { Symptom } \\
\text { duration }\end{array}$} \\
\hline$\geq 7$ years & 8 & 2.4 & $1.9-2.8$ & 0.26 \\
\hline$<7$ years & 5 & 2.1 & $1.8-2.4$ & \\
\hline \multicolumn{5}{|l|}{$\begin{array}{l}\text { Body mass } \\
\text { index }\end{array}$} \\
\hline$\geq 25 \mathrm{~kg} / \mathrm{m}^{2}$ & 7 & 2.2 & $1.8-2.6$ & 0.45 \\
\hline$<25 \mathrm{~kg} / \mathrm{m}^{2}$ & 9 & 2.4 & $2.1-2.8$ & \\
\hline \multicolumn{5}{|l|}{$\operatorname{Age}^{*}$} \\
\hline$\geq 41$ years & 11 & 2.3 & $1.9-2.7$ & 0.79 \\
\hline$<41$ years & 11 & 2.4 & $2.1-2.6$ & \\
\hline
\end{tabular}

${ }^{*}$ Subgroups divided at median value

†Variables sorted from lowest to highest subgroup P value

clinical trials of constipation therapies. Nearly $50 \%$ of patients express dissatisfaction with conventional constipation therapies [9] and clinical trials of alternative treatments are warranted. Accurate estimation of baseline stool frequency and form will help to determine sample size requirements. Third, study design and geography may influence baseline patient characteristics. For example, reported stool frequency was higher when daily diaries were used. This is in line with previous research showing that stool frequency is underestimated unless stool diaries are used [10]. In addition, the reported stool frequency in adults with functional constipation was independently influenced by geographic location. The reasons for this finding are unknown, but they 


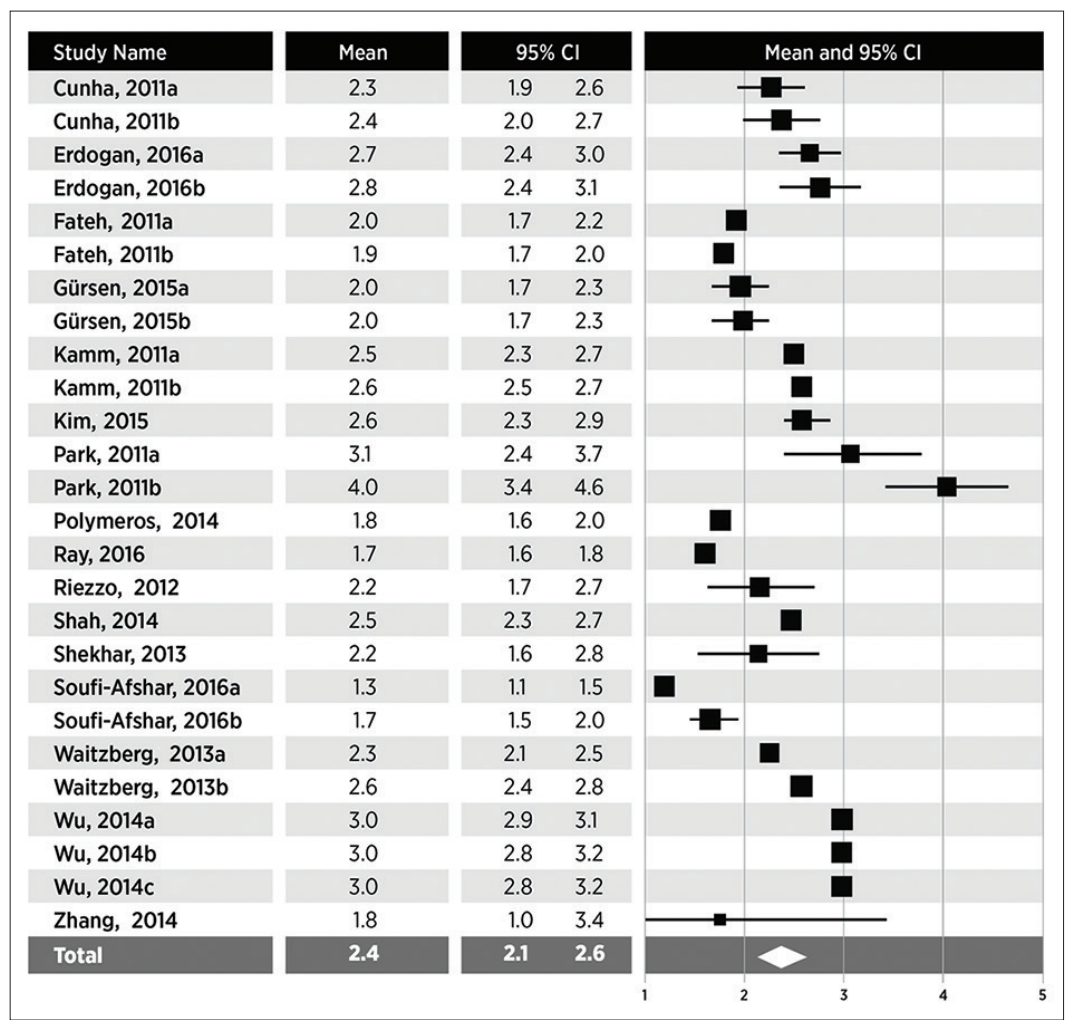

Figure 3 Stool form in adults with functional constipation. Stool form estimates from random effects meta-analysis. A pooled estimate (diamond) and $95 \%$ confidence interval (diamond width) summarizes the effect size

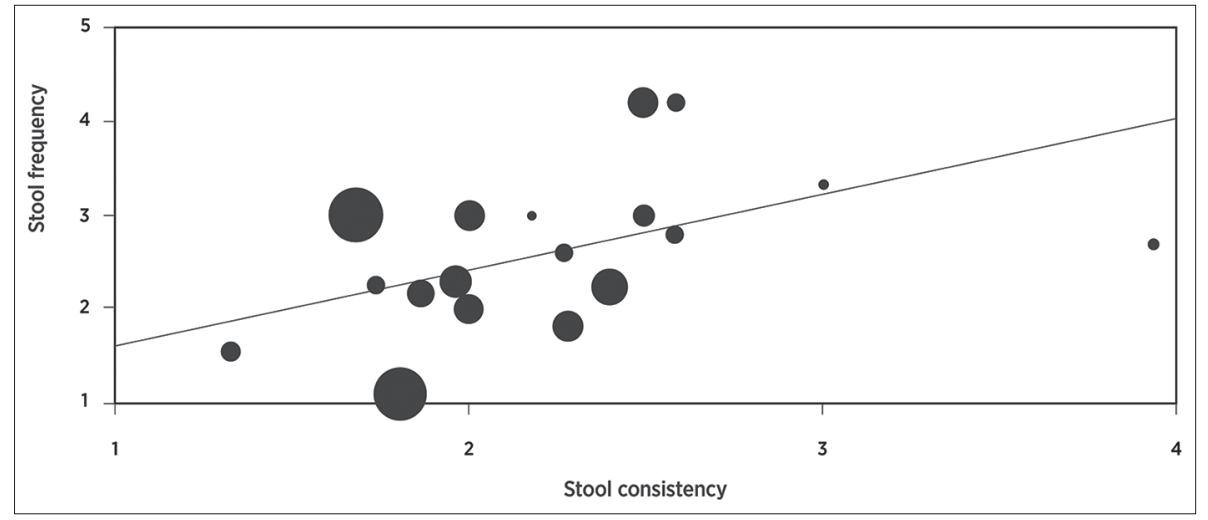

Figure 4 Meta-regression of relationship between stool frequency and form in adults with functional constipation. Percentage of explained variance $=13 \%, \mathrm{P}<0.001$

may be related to unmeasured variables such as diet, lifestyle, or socioeconomic status. Another plausible explanation for this finding could be cultural or geographic differences in the interpretation and reporting of patients' symptoms. Overall, the data presented in this review may assist clinical trialists in estimating baseline symptom severity and provide additional insight into the impact of study design, geography, and patient characteristics on these estimates.

The strengths of this meta-analysis include the use of a consistent diagnostic definition and the exploration of sources of heterogeneity in determining normative values for stool frequency and form in adults with functional constipation.
There are also several important limitations of this research that should be highlighted. Unreported confounding factors, such as temporal symptoms, psychological issues, stress levels, diet, hydration, physical activity, or medical history, may have influenced outcomes. Importantly, these results apply only to adults diagnosed with functional constipation using the Rome III guidelines; therefore, their generalizability to all constipated adults is unknown. Finally, a number of potentially relevant studies were excluded because of insufficient data reporting.

In conclusion, adults with functional constipation according to the Rome III criteria report significant 
variation in stool frequency and form. The variability among studies may be explained by geography and by study design factors.

\section{References}

1. Suares NC, Ford AC. Prevalence of, and risk factors for, chronic idiopathic constipation in the community: systematic review and meta-analysis. Am J Gastroenterol 2011;106:1582-1591.

2. Shekhar C, Monaghan PJ, Morris J, et al. Rome III functional constipation and irritable bowel syndrome with constipation are similar disorders within a spectrum of sensitization, regulated by serotonin. Gastroenterology 2013;145:749-757.

3. Wong RK, Palsson OS, Turner MJ, et al. Inability of the Rome III criteria to distinguish functional constipation from constipation-subtype irritable bowel syndrome. Am J Gastroenterol 2010; 105:2228-2234.

4. Longstreth GF, Thompson WG, Chey WD, Houghton LA, Mearin F, Spiller RC. Functional bowel disorders. Gastroenterology 2006;130:1480-1491.

5. Food and Drug Administration. Guidance for industry: E6 good clinical practice: consolidated guidance. 1996 [cited 2016 September 7]; Available from: http://www.fda.gov/ downloads/Drugs/.../Guidances/ucm073122.pdf.

6. Lewis SJ, Heaton KW. Stool form scale as a useful guide to intestinal transit time. Scand J Gastroenterol 1997;32:920-924.

7. Higgins JP, Thompson SG, Deeks JJ, Altman DG. Measuring inconsistency in meta-analyses. BMJ 2003;327:557-560.

8. Saad RJ, Rao SS, Koch KL, et al. Do stool form and frequency correlate with whole-gut and colonic transit? Results from a multicenter study in constipated individuals and healthy controls. Am J Gastroenterol 2010;105:403-411.

9. Johanson JF, Kralstein J. Chronic constipation: a survey of the patient perspective. Aliment Pharmacol Ther 2007;25:599-608.

10. Sandler RS, Drossman DA. Bowel habits in young adults not seeking health care. Dig Dis Sci 1987;32:841-845.

11. Bian ZX, Cheng CW, Zhu LZ. Chinese herbal medicine for functional constipation: a randomised controlled trial. Hong Kong Med J 2013;19 Suppl 9:44-46.

12. Cunha GH, Fechine FV, Santos LK, et al. Efficacy of the tincture of jalapa in the treatment of functional constipation: a doubleblind, randomized, placebo-controlled study. Contemp Clin Trials 2011;32:153-159.

13. Elsagh M, Fartookzadeh MR, Kamalinejad M, et al. Efficacy of the Malva sylvestris L. flowers aqueous extract for functional constipation: a placebo-controlled trial. Complement Ther Clin Pract 2015;21:105-111.

14. Emami Alorizi SM, Fattahi MR, Saghebi SA, et al. Assessment of the impacts of traditional Persian medical schemes and recommendations on functional chronic constipation compared to a classic medicine lactulose, a randomized clinical trial. J Complement Integr Med 2015;12:325-331.

15. Erdogan A, Rao SS, Thiruvaiyaru D, et al. Randomised clinical trial: mixed soluble/insoluble fibre vs. psyllium for chronic constipation. Aliment Pharmacol Ther 2016;44:35-44.

16. Fateh R, Iravani S, Frootan M, Rasouli MR, Saadat S. Synbiotic preparation in men suffering from functional constipation: a randomised controlled trial. Swiss Med Wkly 2011;141:w13239.

17. Favretto DC, Pontin B, Moreira TR. Effect of the consumption of a cheese enriched with probiotic organisms (Bifidobacterium lactis bi-07) in improving symptoms of constipation. Arq Gastroenterol 2013;50:196-201.

18. Gürsen C, Kerem Günel M, Kaya S, Kav T, Akbayrak T. Effect of connective tissue manipulation on symptoms and quality of life in patients with chronic constipation: a randomized controlled trial. J Manipulative Physiol Ther 2015;38:335-343.

19. Iqbal F, Thomas GP, Tan E, et al. Transcutaneous sacral electrical stimulation for chronic functional constipation. Dis Colon Rectum 2016;59:132-139.

20. Jayasimhan S, Yap NY, Roest Y, Rajandram R, Chin KF. Efficacy of microbial cell preparation in improving chronic constipation: a randomized, double-blind, placebo-controlled trial. Clin Nutr 2013;32:928-934.

21. Kamm MA, Mueller-Lissner S, Wald A, Richter E, Swallow R, Gessner U. Oral bisacodyl is effective and well-tolerated in patients with chronic constipation. Clin Gastroenterol Hepatol 2011;9:577583.

22. Kim SE, Choi SC, Park KS, et al; Constipation Research group of Korean Society of Neurogastroenterology and Motility. Change of fecal flora and effectiveness of the short-term VSL\#3 probiotic treatment in patients with functional constipation. J Neurogastroenterol Motil 2015;21:111-120.

23. Ojetti V, Ianiro G, Tortora A, et al. The effect of Lactobacillus reuteri supplementation in adults with chronic functional constipation: a randomized, double-blind, placebo-controlled trial. J Gastrointestin Liver Dis 2014;23:387-391.

24. Park JE, Sul JU, Kang K, Shin BC, Hong KE, Choi SM. The effectiveness of moxibustion for the treatment of functional constipation: a randomized, sham-controlled, patient blinded, pilot clinical trial. BMC Complement Altern Med 2011;11:124.

25. Polymeros D, Beintaris I, Gaglia A, et al. Partially hydrolyzed guar gum accelerates colonic transit time and improves symptoms in adults with chronic constipation. Dig Dis Sci 2014;59:2207-2214.

26. Ray G. Evaluation of the symptom of constipation in Indian patients. J Clin Diagn Res 2016;10:OC01-OC03.

27. Riezzo G, Orlando A, D’Attoma B, et al. Randomised clinical trial: efficacy of Lactobacillus paracasei-enriched artichokes in the treatment of patients with functional constipation-a doubleblind, controlled, crossover study. Aliment Pharmacol Ther 2012;35:441-450.

28. Shah N, Baijal R, Kumar $P$, et al. Clinical and investigative assessment of constipation: a study from a referral center in western India. Indian J Gastroenterol 2014;33:530-536.

29. Somi MH, Bagheri M, Ghojazadeh M. Efficacy of an Iranian herbal preparation (Lax-Asab) in treating functional constipation: a randomized, placebo-controlled clinical trial. J Tradit Complement Med 2015;5:153-156.

30. Soufi-Afshar I, Moghadamnia A, Bijani A, Kazemi S, ShokriShirvani J. Comparison of pyridostigmine and bisacodyl in the treatment of refractory chronic constipation. Caspian J Intern Med 2016;7:19-24.

31. Waitzberg DL, Logullo LC, Bittencourt AF, et al. Effect of synbiotic in constipated adult women - a randomized, double-blind, placebocontrolled study of clinical response. Clin Nutr 2013;32:27-33.

32. Wu J, Liu B, Li N, et al. Effect and safety of deep needling and shallow needling for functional constipation: a multicenter, randomized controlled trial. Medicine (Baltimore) 2014;93:e284.

33. Yeun Y, Lee J. Effect of a double-coated probiotic formulation on functional constipation in the elderly: a randomized, double blind, controlled study. Arch Pharm Res 2015;38:1345-1350.

34. Zhang N, Huang Z, Xu F, et al. Transcutaneous neuromodulation at posterior tibial nerve and ST36 for chronic constipation. Evid Based Complement Alternat Med 2014;2014:560802. 